\title{
Optimization and integration of nanosilver on polycaprolactone nanofibrous mesh for bacterial inhibition and wound healing in vitro and in vivo
}

This article was published in the following Dove Press journal:

International Journal of Nanomedicine

12 September 2017

Number of times this article has been viewed

\author{
Menglong Liu',2 \\ Gaoxing Luo',2 \\ Ying Wang ${ }^{1,2}$ \\ Weifeng $\mathrm{He}^{1,2}$ \\ Tengfei Liu ${ }^{1,2}$ \\ Daijun Zhou' ${ }^{1,2}$ \\ Xiaohong $\mathrm{Hu}^{1,2}$ \\ Malcolm Xing ${ }^{1,3}$ \\ Jun $\mathrm{Wu}^{1,2,4}$
}

'State Key Laboratory of Trauma, Burn and Combined Injury, Institute of Burn Research, Southwest Hospital, the Third Military Medical University, ${ }^{2}$ Department of Burns, Chongqing Key Laboratory for Disease Proteomics, Chongqing, People's Republic of China; ${ }^{3}$ Department of Mechanical Engineering, University of Manitoba, Winnipeg, MB, Canada; ${ }^{4}$ Department of Burns, the First Affiliated Hospital of Sun Yat-Sen University, Guangzhou, People's Republic of China
Correspondence: Malcolm Xing; Jun Wu State Key Laboratory of Trauma, Burn and Combined Injury, Institute of Burn Research, Southwest Hospital, the Third Military Medical University, 30 Gaotanyan Street, Shapingba District, Chongqing 400038, People's Republic of China Tel +86236875 4l $48 ;+862368754173$ Email malcolm.xing@umanitoba.ca; editorinchief@burninchina.com
Abstract: Bacterial infection is a major hurdle to wound healing, and the overuse of antibiotics have led to global issue, such as emergence of multidrug-resistant bacteria, even "super bacteria". On the contrary, nanosilver (NS) can kill bacteria without causing resistant bacterial strains. In this study, NS was simply generated in situ on the polycaprolactone (PCL) nanofibrous mesh using an environmentally benign and mussel-inspired dopamine (DA). Scanning electron microscopy showed that NS uniformly formed on the nanofibers of PCL mesh. Fourier transform infrared spectroscopy revealed the step-by-step preparation of pristine PCL mesh, including DA coating and NS formation, which were further verified by water contact angle changing from hydrophobic to hydrophilic. To optimize the NS dose, the antibacterial activity of PCL/NS against Staphylococcus aureus, Escherichia coli and Acinetobacter baumannii was detected by bacterial suspension assay, and the cytotoxicity of NS was evaluated using cellular morphology observation and Cell Counting Kit-8 (CCK8) assay. Then, inductively coupled plasma atomic emission spectrometry exhibited that the optimized PCL/NS had a safe and sustained silver release. Moreover, PCL/NS could effectively inhibit bacterial infection in an infectious murine full-thickness skin wound model. As demonstrated by the enhanced level of proliferating cell nuclear antigen (PCNA) in keratinocytes and longer length of neo-formed epidermis, PCL/NS accelerated wound healing by promoting re-epithelialization via enhancing keratinocyte proliferation in infectious wounds.

Keywords: polycaprolactone nanofibrous mesh, mussel inspired, nanosilver, anti-infection activity, wound healing, re-epithelialization

\section{Introduction}

Bacterial infection is considered as the main hurdle to natural wound healing process. ${ }^{1-3}$ Antibiotics are generally used to provide the antibacterial activity in the clinical setting, but their overuse has caused antibiotic resistance to bacterial pathogens, which further led to the emergence of multidrug-resistant (MDR) bacteria. ${ }^{4,5}$ Thus, an alternative solution is urgently needed.

Silver materials, such as nanosilver (NS) with nanodimensions of 1-100 nm and silver nanoclusters with ultrasmall size of $<2 \mathrm{~nm}$, which possess excellent antibacterial activity, have attracted great interest to solve the antibiotic resistance problem recently. ${ }^{6,7}$ Specifically, NS has a broad-spectrum antimicrobial activity and highly killing efficacy by destroying the bacterial DNA and membrane, as well as inhibiting respiratory enzyme activity. ${ }^{8}$ More importantly, few studies have reported that bacteria were resistant to NS, so NS is a promising candidate to replace antibiotics. ${ }^{8,9}$ However, the cytotoxicity of silver nanoparticles (AgNPs) has aroused public vigilance in 


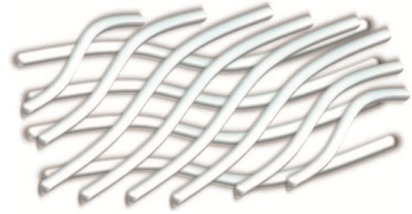

PCL

\section{$\underset{\mathrm{pH}=8.5,16 \mathrm{~h}}{\stackrel{\mathrm{DA}}{\longrightarrow}}$}

In vivo



Wound healing improvement

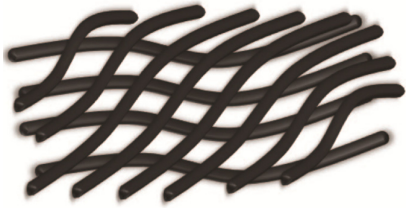

PCL/DA

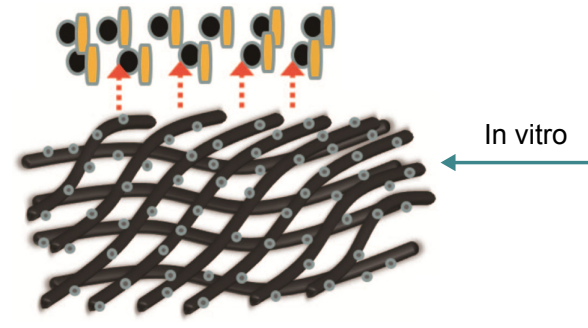

Bacterial inhibition

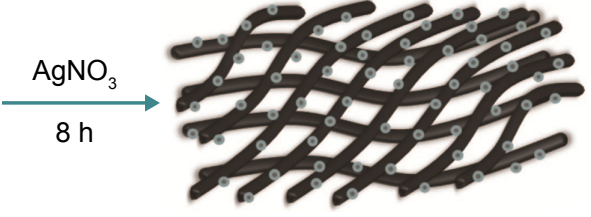

PCL/NS
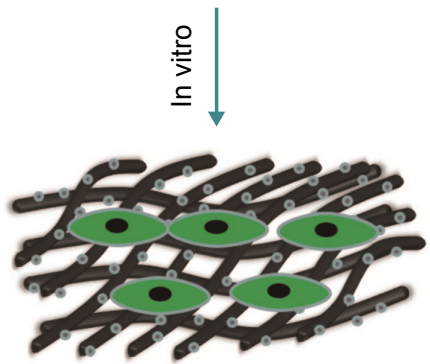

Cytotoxicity assessment

Figure I Illustrative diagrams of the procedure for PCL/NS preparation and the biological effect of PCL/NS in vitro and in vivo. Abbreviations: $\mathrm{AgNO}_{3}$, silver nitrate; DA, dopamine; NS, nanosilver; $\mathrm{PCL}$, polycaprolactone.

recent years. ${ }^{10}$ Several reports have found that the potential toxic effect caused by NS occurred only at high concentrations, and incorporated NS into biomaterials probably reduce the toxicity of NS. ${ }^{11-13}$ Consequently, it is available to incorporate an optimized concentration of NS into a material to prepare an antibacterial wound dressing without cytotoxicity.

Another essential problem that needs to be taken into account is the NS synthetic method. Generally, NS is prepared using physical or chemical synthetic strategies. Nevertheless, the conventional physical methods are low yield and high energy consumption, and the general chemical methods are expensive and toxic to environment. ${ }^{14-16}$ This makes an easy and environmentally friendly way to generate NS, which is very desirable for the extended application of NS. Recently, dopamine (DA) is found to be gently self-polymerized under alkaline condition because of its mussel adhesive property, and the formed polydopamine (PD) coating possesses super adhesive ability and strong reduction property. ${ }^{17,18}$ Only by the coating of DA, silver ion will be efficiently reduced to NS and then immobilized on the surface of biomaterials. ${ }^{19}$ Furthermore, DA has been well demonstrated to be biocompatible and nontoxic to human body. ${ }^{20,21}$ Therefore, DA coating is an ideal way to prepare NS.

Apart from the antibacterial property, good biocompatibility and promotion of re-epithelialization are also important factors for an ideal wound dressing. ${ }^{22,23}$ Polycaprolactone (PCL) is a biocompatible and biodegradable material approved by the US Food and Drug Administration (FDA). ${ }^{24,25}$ The electrospun PCL nanofibrous mesh possesses high porosity and good mechanical strength, which are important factors for wound dressings. ${ }^{22,26,27}$ Moreover, the high specific surface area and interwoven nanofibers endow PCL nanofibrous mesh enough space for antibacterial agents residing. ${ }^{28}$ Due to these attributes, PCL nanofibrous mesh is a predominant substrate to accommodate NS for an antibacterial wound dressing.

The aim of this study was to prepare a biocompatible and antibacterial wound dressing without increasing bacterial resistance. Hence, we assumed, in situ, different doses of synthesized NS on the PCL nanofibrous mesh using eco-friendly DA (Figure 1). Then, the screening of optimized PCL/NS was determined by antibacterial activity and cytotoxicity test. Finally, the efficacy of PCL/NS on infectious wounds in vivo was also adequately investigated.

\section{Materials and methods Materials}

PCL (molecular weight [MW] =70,000), dimethylformamide (DMF) and dichloromethane were purchased from SigmaAldrich Co. (St Louis, MO, USA). DA hydrochloride was purchased from Solarbio Science \& Technology Co., Ltd. (Beijing, People's Republic of China). Silver nitrate $\left(\mathrm{AgNO}_{3}\right)$ was purchased from Sangon (Shanghai, People's Republic of China). 
Animals were purchased from the Experimental Animal Department of the Third Military Medical University. All the experimental protocols were approved by the Institutional Animal Care and Use Committee of the Third Military Medical University, and all methods were performed according to the guidelines of the Third Military Medical University.

\section{Preparation of the PCL/NS nanofibrous mesh}

PCL nanofibrous mesh was fabricated using an electrospinning process as previously described. ${ }^{26} \mathrm{PCL}$ was first dissolved in $\mathrm{DMF} /$ dichloromethane $(1: 4, \mathrm{v} / \mathrm{v})$ at a concentration of $10 \mathrm{wt} \%$; then, the electrospinning process was carried out with the following parameters: applied voltage, $18 \mathrm{kV}$; solution feed rate, $1.2 \mathrm{~mL} / \mathrm{h}$; spinning time, $4 \mathrm{~h}$; syringe needle gage, $21 \mathrm{G}$; distance between needle and collector, $15 \mathrm{~cm}$. Subsequently, PCL nanofibrous mesh was immersed in a DA solution ( $2 \mathrm{mg} / \mathrm{mL}$ in $10 \mathrm{mM}$ Tris-HCL, $\mathrm{pH} 8.5)$ at $25^{\circ} \mathrm{C}$ for $16 \mathrm{~h}$. Finally, the DA-coated mesh was immersed in an aqueous silver nitrate solution $\left(\mathrm{AgNO}_{3}\right)$ at different concentrations $(0.5 \mathrm{mM}, 1 \mathrm{mM}, 2 \mathrm{mM})$ for $8 \mathrm{~h}$ in darkness at $25^{\circ} \mathrm{C}$. Then, the specimens were washed with $\mathrm{DDH}_{2} \mathrm{O}$ three times to remove the residual silver ions and dried at $37^{\circ} \mathrm{C}$. The DA- and $\mathrm{AgNO}_{3}$-treated specimens were indicated as PCL/DA, PCL/NS0.5, PCL/NS1.0 and PCL/NS2.0, which are discussed in the following sections.

\section{Characterization of the PCL/NS nanofibrous mesh}

The morphology and structure of PCL/NS nanofibrous mesh were observed using scanning electron microscopy (SEM; Hitachi S-3400N; Hitachi Ltd., Tokyo, Japan), and the diameter of NS was measured using ImageJ software by two independent researchers (five SEM images). The chemical structure of the surface of PCL, PCL/DA and PCL/NS were characterized using a PerkinElmer Fourier transform infrared (FTIR) spectrometer (100S). The water contact angle was investigated by a contact angle analyzer (Theta Lite 101; Biolin Scientific, Stockholm, Sweden).

\section{Bacterial suspension assay and determination of biofilm formation}

The bacterial suspension assay was adapted from previous report with a little modification..$^{29}$ The commercial bacterial strains including Staphylococcus aureus (American Type Culture Collection [ATCC] 25923, Manassas, VA, USA), Escherichia coli (ATCC 25922) and Acinetobacter baumannii (ATCC 19606) were used for this assay. The S. aureus and
E. coli are nondrug-resistant bacteria, and the A. baumannii is a multidrug-resistant bacterium. Briefly, the log-phase bacterial suspension of $S$. aureus, E. coli and A. baumannii was first diluted at the predetermined starting concentration (optical density [OD] at $600 \mathrm{~nm}$; $\mathrm{OD}_{600}=0.07$ ) in LuriaBertani (LB) medium. Then, $250 \mu \mathrm{L}$ of diluted bacterial solution was added into each well of a 48-well plate, and the sterilized PCL, PCL/DA, PCL/NS0.5, PCL/NS1.0 and PCL/NS2.0 samples, $8 \times 8 \mathrm{~mm}$ in size, were separately immersed in the bacterial solution. Finally, the 48 -well plate was kept at $37^{\circ} \mathrm{C}$ in a shaker incubator under $50 \mathrm{rpm}$ for $24 \mathrm{~h}$. To detect the number of bacteria, $100 \mu \mathrm{L}$ of bacterial solution was transferred into a 96-well plate, and the $\mathrm{OD}_{600}$ value was measured. To further evaluate the inhibition efficiency of NS, the bacterial solution after co-incubation was diluted $10,000 \times$ in saline solution and $10 \mu \mathrm{L}$ of diluted solution was uniformly coated on Mueller-Hinton agar plate. After $24 \mathrm{~h}$ of incubation at $37^{\circ} \mathrm{C}$, the bacterial colonies on agar plate were photographed. In this study, untreated bacterial solution was served as the negative control group, and the PCL and PCL/DA groups were served as the control groups.

To further detect the formation of biofilms on the surfaces of these samples, the PCL, PCL/DA, PCL/NS0.5, PCL/NS1.0 and PCL/NS2.0 films were observed under SEM, and the areas covered by biofilms or bacteria were measured using IPP 6.0 software as previously described. ${ }^{30,31}$

\section{In vitro cytotoxicity test}

Green fluorescent protein (GFP) transgenic neonatal mice (1-3 days) were obtained from the Experimental Animal Department of the Third Military Medical University, and the experimental protocol was approved by the Institutional Animal Care and Use Committee of the Third Military Medical University. The fibroblasts were isolated from the neonatal mice according to the previous study ${ }^{32}$ Briefly, the skin tissue of neonatal mice was immersed in $0.5 \mathrm{mg} / \mathrm{mL}$ Dispase II (Sigma-Aldrich Co.) at $4^{\circ} \mathrm{C}$ overnight to separate the epidermis and dermis. Then, the isolated dermis was minced and digested by trypsin $(0.25 \mathrm{mg} / \mathrm{mL}$; Boster, Wuhan, People's Republic of China) for 10 min. Subsequently, $3 \times$ Dulbecco's Modified Eagle's Medium (DMEM; Thermo Fisher Scientific, Waltham, MA, USA) containing 10\% fetal bovine serum (FBS; Thermo Fisher Scientific) was added to terminate the digestion. Finally, after the mixture solution centrifuged at 1,000 rpm for $6 \mathrm{~min}$, the cells were harvested and incubated in DMEM containing 10\% FBS, penicillin $(100 \mathrm{U} / \mathrm{mL})$ and streptomycin $(100 \mu \mathrm{g} / \mathrm{mL})$ at $37^{\circ} \mathrm{C}$ in an incubator containing $5 \% \mathrm{CO}_{2}$. 
The third-passage fibroblasts were seeded on the films as follows. First, the PCL/DA, PCL/NS0.5, PCL/NS1.0 and PCL/NS2.0 films were punched into $6 \mathrm{~mm}$-diameter disks. Second, after sterilized with $75 \%$ alcohol, the disks were washed with phosphate-buffered solution (PBS) three times and then placed into each well of a 96-well plate. Third, 3,000 prepared fibroblasts in $100 \mu \mathrm{L}$ DMEM containing $10 \%$ FBS were added into each well. At days 1, 3, 5 post seeding, the films were transferred into another 96-well plate, and $100 \mu \mathrm{L}$ of DMEM together with $10 \mu \mathrm{L}$ Cell Counting Kit-8 (CCK8) solution was added to each well. After incubation at $37^{\circ} \mathrm{C}$ for $2 \mathrm{~h}$, the films were removed, and the absorbance of reserved solution was measured at $450 \mathrm{~nm}$ by an enzymelinked immunosorbent assay reader (Thermo Varioskan Flash, Winooski, VT, USA). Moreover, the morphology of cells on the films at day 3 post seeding was observed by a fluorescence microscopy (Olympus Corporation, Tokyo, Japan).

\section{Silver ion release test}

The PCL/NS1.0 films were each cut into $(10 \times 10 \mathrm{~mm})$ pieces $(\mathrm{n}=3)$ and immersed in $6 \mathrm{~mL}$ of PBS in darkness at $37^{\circ} \mathrm{C}$. At each predetermined time point, ie, days 1, 3, 5 and 7, the corresponding PBS was entirely harvested and analyzed by inductively coupled plasma atomic emission spectrometry (ICP-AES; Leeman, Hudson, NH, USA).

\section{In vivo wound healing assessment}

$\mathrm{BALB} / \mathrm{c}$ adult mice (male, 20-25 g) used in the experiment were acquired from the Experimental Animal Department of the Third Military Medical University. The animals were individually raised in plastic cages under standardized conditions (room temperature, $25^{\circ} \mathrm{C}$; relative humidity, $50 \%$; circadian rhythm, $12 \mathrm{~h}$ ).

The effect of PCL/NS1.0 on wound healing was detected using an infectious murine full-thickness skin defect wound model based on previous reports with a slight modification. ${ }^{33,34}$ $\mathrm{BALB} / \mathrm{c}$ mice were individually anesthetized using an intraperitoneal injection of $1 \%$ pentobarbital; then, the dorsal surface was shaved. After rinsed with 75\% alcohol, two $6 \mathrm{~mm}$-diameter full-thickness wounds were prepared using a sterile $6 \mathrm{~mm}$ punch biopsy tool on either side of the back. Immediately, bacterial suspension of $E$. coli $(10 \mu \mathrm{L})$ and $S$. aureus $(10 \mu \mathrm{L})$, which were standardized to $0.5 \mathrm{McFar}-$ land standards $\left(10^{8}\right.$ colony-forming units $\left.[\mathrm{CFU}] / \mathrm{mL}\right)$, was dropped on the surface of each wound. Then, the wounds were photographed by a digital camera to represent the starting wound area. After that, the wounds were covered with sterile PCL, PCL/DA or PCL/NS1.0 films, and an adhesive biological membrane (NPWT-1, Negative Pressure Wound Therapy Kit; VSD Bio-Tech Co., Wuhan, People's Republic of China) was used to keep the position. In this study, the mice that had not treated with bacterial suspension and wound dressing were regarded as the blank group, while the mice that had treated only with bacterial suspension were regarded as the control group. Finally, the wounds were photographed at days 1, 3, 5 and 7 post surgery, and the nonhealing wound areas were carefully measured using IPP 6.0 software by two independent researchers. The closed wound area was calculated using the following formula: ${ }^{35}$

$$
\% \text { of closed wound area }=\frac{(I-R)}{I} \times 100 \% \text {. }
$$

where $I$ refers to the number of pixels of the starting wound area, and $R$ refers to the number of pixels of the nonhealing wound area at the predetermined time.

\section{Hematoxylin-eosin (H\&E) staining}

The cutaneous wound tissues $(10 \times 10 \mathrm{~mm})$ were carefully harvested from mice sacrificed at day 7 post surgery. After fixing with $4 \%$ paraformaldehyde for $24 \mathrm{~h}$, the tissues were embedded in paraffin and sliced at a thickness of $5 \mu \mathrm{m}$, then stained with H\&E. The length of the newly generated epidermis, which is defined as the distance from the border between unwounded skin tissue and wound area to the advancing edges of the epidermis, ${ }^{36}$ was measured using ImageJ software. The number of inflammatory cells infiltrated in the wound edge was counted using ImageJ software as previously described. ${ }^{37}$ All measurements using software were performed by two independent researchers.

\section{Immunohistochemistry}

The expression of proliferating cell nuclear antigen (PCNA) in keratinocytes at day 7 post surgery was detected by immunohistochemistry. Briefly, after deparaffinized and rehydrated, the wound tissue sections were incubated at $95^{\circ} \mathrm{C}$ in a sodium citrate buffer bath for heat-mediated antigen retrieval. Then, the sections were incubated with $3 \% \mathrm{H}_{2} \mathrm{O}_{2}$ at $25^{\circ} \mathrm{C}$. After 15 min of incubation, the sections were washed with PBS three times, and then blocked in 10\% normal goat serum (Zhongshan Bio-Tech Co., Ltd., Guangdong, People's Republic of China) at $37^{\circ} \mathrm{C}$ for $30 \mathrm{~min}$, followed by incubation with primary antibody (anti-PCNA antibody ab15497, 1:200 dilution; Abcam, Cambridge, UK) at $4^{\circ} \mathrm{C}$ overnight. Subsequently, after being washed with PBS three times, the sections were incubated with biotinylated goat anti-rabbit IgG antibody 
(Zhongshan Bio-Tech Co., Ltd.) at $37^{\circ} \mathrm{C}$ for $30 \mathrm{~min}$. Then, the sections were further incubated with avidin-peroxidase reagent (Zhongshan Bio-Tech Co., Ltd.) at $37^{\circ} \mathrm{C}$ for $30 \mathrm{~min}$. Finally, the sections were stained with 3,3'-diaminobenzidine tetrahydrochloride and hematoxylin. The sections were photographed under an optical microscope (CTR6000; Leica Microsystems, Wetzlar, Germany), and the number of PCNApositive keratinocytes per field in the newly formed epidermis was counted by two independent researchers.

\section{Statistical analysis}

Data are presented as mean \pm SD and analyzed by one-way ANOVA. Statistical significance was accepted at $p<0.05$ $(* p<0.05$ and $* * p<0.01)$.

\section{Results}

\section{Characterization of PCL/NS nanofibrous mesh}

SEM images of the PCL, PCL/DA, PCL/NS0.5, PCL/NS1.0 and PCL/NS2.0 are shown in Figure 2. The native PCL film was composed of a nanofibrous network, and the diameter of the nanofibers ranged from $200 \mathrm{~nm}$ to $1,000 \mathrm{~nm}$. No significant change was observed in the morphology after DA coating, except that the nanofibers of PCL/DA were a bit rougher than that of pristine PCL. However, it was clearly seen that plenty of AgNPs were uniformly distributed on the nanofibers of PCL/NS0.5, PCL/NS1.0 and PCL/NS2.0 films, as shown in Figure $2 \mathrm{C}-\mathrm{E}$, and the density of NS gradually increased with the increase of the concentration of $\mathrm{AgNO}_{3}$ rising. As shown in Figure 2F, the average diameter of NS measured by ImageJ software was $73.3 \pm 33.6 \mathrm{~nm}, 74.3 \pm 30.4 \mathrm{~nm}$ and $72.2 \pm 26.3 \mathrm{~nm}$ in PCL/NS0.5, PCL/NS1.0 and PCL/NS2.0 films, respectively, and no significant difference was observed among them.

FTIR analysis of the PCL, PCL/DA, PCL/NS0.5, PCL/ NS1.0 and PCL/NS2.0 films is shown in Figure 3. In PCL spectrum, two characteristic absorption peaks at $1,166 \mathrm{~cm}^{-1}$ and $1,726 \mathrm{~cm}^{-1}$ were related to $\mathrm{C}-\mathrm{O}-\mathrm{C}$ and $\mathrm{C}=\mathrm{O}$ bonds, and peaks at $2,864 \mathrm{~cm}^{-1}$ and $2,930 \mathrm{~cm}^{-1}$ corresponded to the $\mathrm{C}-\mathrm{H}$ bond. ${ }^{33,38,39}$ After DA coating, a broad peak around $3,100-3,600 \mathrm{~cm}^{-1}$ corresponding to the stretching vibration band of phenolic hydroxyls was observed in the spectrum of PCL/DA. ${ }^{13}$ The peak became sharper in the PCL/NS0.5, PCL/NS1.0 and PCL/NS2.0 spectra, suggesting the interaction between NS and DA. ${ }^{40}$ In addition, the stronger peaks at $1,166 \mathrm{~cm}^{-1}, 1,726 \mathrm{~cm}^{-1}$ and 2,930 $\mathrm{cm}^{-1}$ also indicated the deposition of NS on the PCL nanofibers.

As shown in Figure 4, the water contact angle of PCL, PCL/DA, PCL/NS0.5, PCL/NS1.0 and PCL/NS2.0 was $107.9^{\circ} \pm 1.2^{\circ}, 27.7^{\circ} \pm 1.7^{\circ}, 25.7^{\circ} \pm 3.8^{\circ}, 27.5^{\circ} \pm 4.0^{\circ}$ and $29.2^{\circ} \pm 3.0^{\circ}$, respectively.

\section{In vitro antibacterial property of PCL/NS}

A bacterial suspension assay was used to detect the antibacterial activity of PCL, PCL/DA, PCL/NS0.5, PCL/NS1.0 and PCL/NS2.0 films. After $24 \mathrm{~h}$ of incubation with bacterial
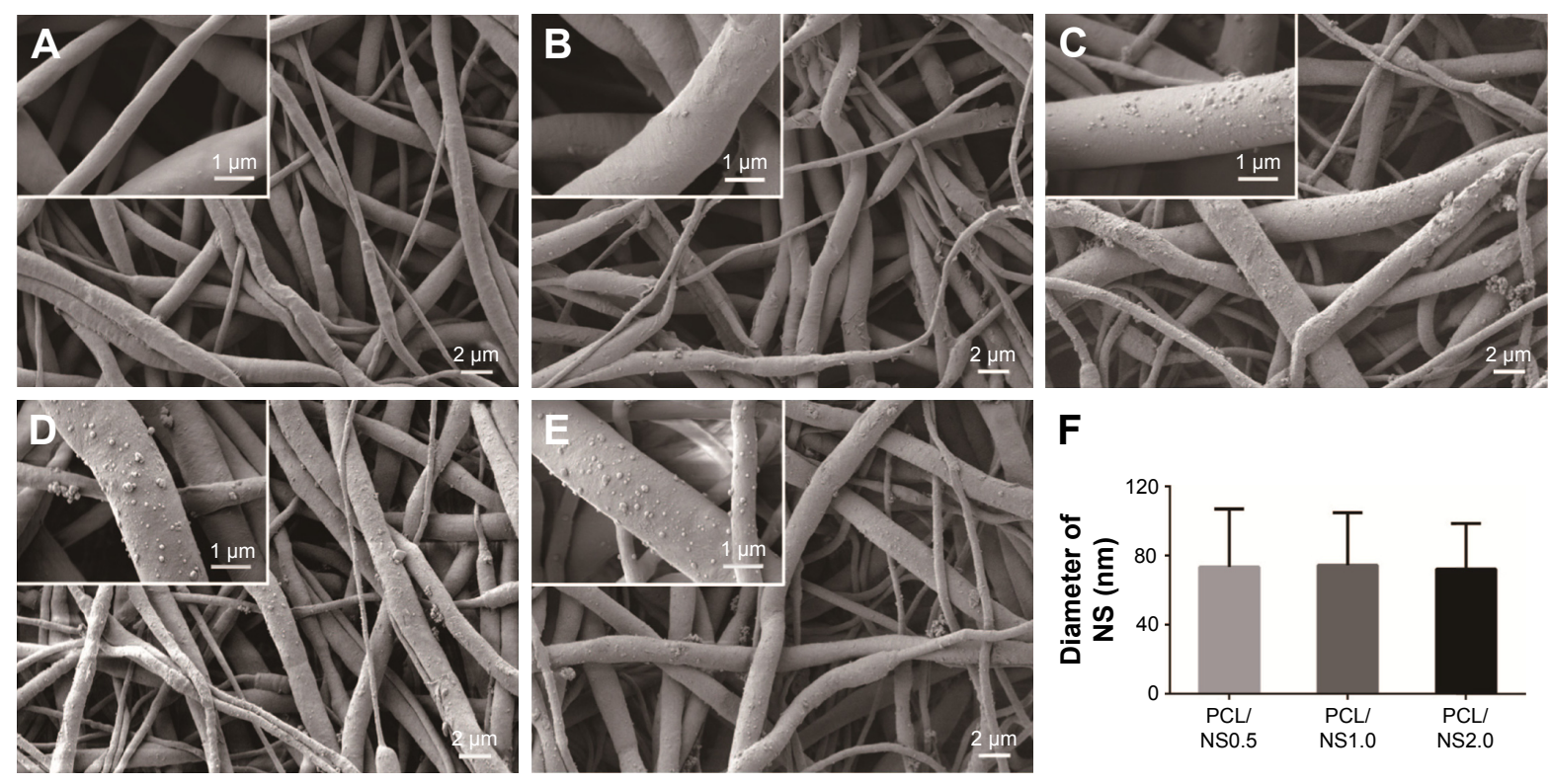

$\mathbf{F}$

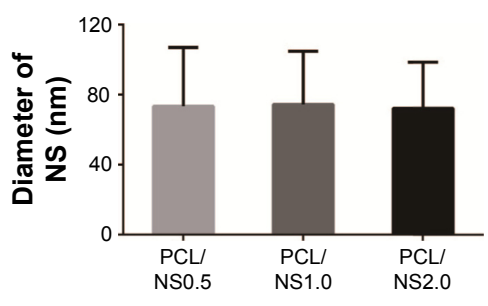

Figure 2 Morphology of (A) PCL, (B) PCL/DA, (C) PCL/NS0.5, (D) PCL/NSI.0 and (E) PCL/NS2.0; (F) the diameter of NS ( $n=5$ ).

Notes: Magnification of images $\times 3,000$; magnification of insets $\times 15,000$.

Abbreviations: DA, dopamine; NS, nanosilver; PCL, polycaprolactone. 




Figure 3 FTIR spectra of the following: A, PCL; B, PCL/DA; C, PCL/NS0.5; D, PCL/ NSI.0; E, PCL/NS2.0 ( $n=3)$.

Abbreviations: DA, dopamine; FTIR, Fourier transform infrared; NS, nanosilver; $\mathrm{PCL}$, polycaprolactone.

suspensions, the $\mathrm{OD}_{600}$ values of the PCL/NS1.0 and PCL/NS2.0 groups were significantly lower than those of the control, PCL, PCL/DA and PCL/NS0.5 groups for S. aureus, E. coli and A. baumannii (Figure 5A-C). No significance was observed in the $\mathrm{OD}_{600}$ values between the PCL/NS1.0 and PCL/NS2.0 groups. Furthermore, in line with the $\mathrm{OD}_{600}$ values, the numbers of bacterial colonies cultured from the co-incubation suspension of $S$. aureus, E. coli and A. baumannii (Figure 5D-I) were obviously more in the control, PCL, PCL/DA and PCL/NS0.5 groups than those in the PCL/NS1.0 and PCL/NS2.0 groups.

The bacteria can adhere to a surface and secrete a polymeric substance matrix to form biofilms, which protect bacteria from external harm such as antibiotics. ${ }^{41,42}$ Therefore, it is important for a wound dressing to inhibit the formation of biofilms when covered on the wound. ${ }^{1}$ To further investigate the formation of biofilms on the surfaces of PCL, PCL/DA, PCL/NS0.5, PCL/NS1.0 and PCL/NS2.0 films, the samples after co-incubation with bacteria were observed by SEM, and the areas covered by biofilms or bacteria were measured. As shown in Figure 6, extensive bacterial colonization produced by the proliferation of $S$. aureus, E. coli or
A. baumannii was grouped on the surfaces of PCL, PCL/DA and PCL/NS0.5 films, and partial bacteria were encased in the polymeric matrix, which suggested the formation of biofilms. ${ }^{43,44}$ In contrast, even though several bacteria could be observed on the surfaces of PCL/NS1.0 and PCL/NS2.0 films, no obvious polymeric matrix was found around the $S$. aureus, E. coli and A. baumannii bacteria, indicating that PCL/NS1.0 and PCL/NS2.0 could inhibit the formation of biofilms. Moreover, the area covered by the biofilms or bacteria on PCL/NS1.0 and PCL/NS2.0 surfaces were significantly smaller than that on the PCL, PCL/DA and PCL/NS0.5 surfaces.

\section{Cytotoxicity of PCL/NS}

To evaluate the cytotoxicity of NS, cell morphology observation and a CCK8 assay were used. As shown in Figure 7A-C, the fibroblasts at day 3 post seeding showed a characteristic spindle shape with well adhesion and spreading on the PCL/DA, PCL/NS0.5 and PCL/NS1.0 films. However, the number of fibroblasts was obviously less on the PCL/NS2.0 films (Figure 7D). The CCK8 result also showed that the OD value of the PCL/NS2.0 group was significantly lower than the PCL/NS0.5 and PCL/NS1.0 groups at day 3 post seeding (Figure 7E). Nevertheless, no significant differences in the OD values were observed among the PCL/DA, PCL/NS0.5 and PCL/NS1.0 groups.

Taking the results of bacterial suspension assay and cytotoxicity evaluation into account, the PCL/NS1.0 that showed excellent antibacterial property and biocompatibility was selected as the optimized film for the following experiments.

\section{Silver ion release in PBS}

Silver ions released from PCL/NS1.0 were detected at days 1, 3, 5 and 7 in PBS by ICP-AES (Figure 8). At day 1, a burst release of silver ions was observed, whose concentration was about $0.32 \mu \mathrm{g} / \mathrm{mL}$. Then, the silver ions gradually released slowly in the following time points. After 7 days, sustained silver ion release could still be observed, and the total released concentration of silver ions was up to $0.57 \mu \mathrm{g} / \mathrm{mL}$.



Figure 4 Water contact angle of (A) PCL, (B) PCL/DA, (C) PCL/NS0.5, (D) PCL/NSI.0 and (E) PCL/NS2.0 (n=3). Abbreviations: DA, dopamine; NS, nanosilver; PCL, polycaprolactone. 

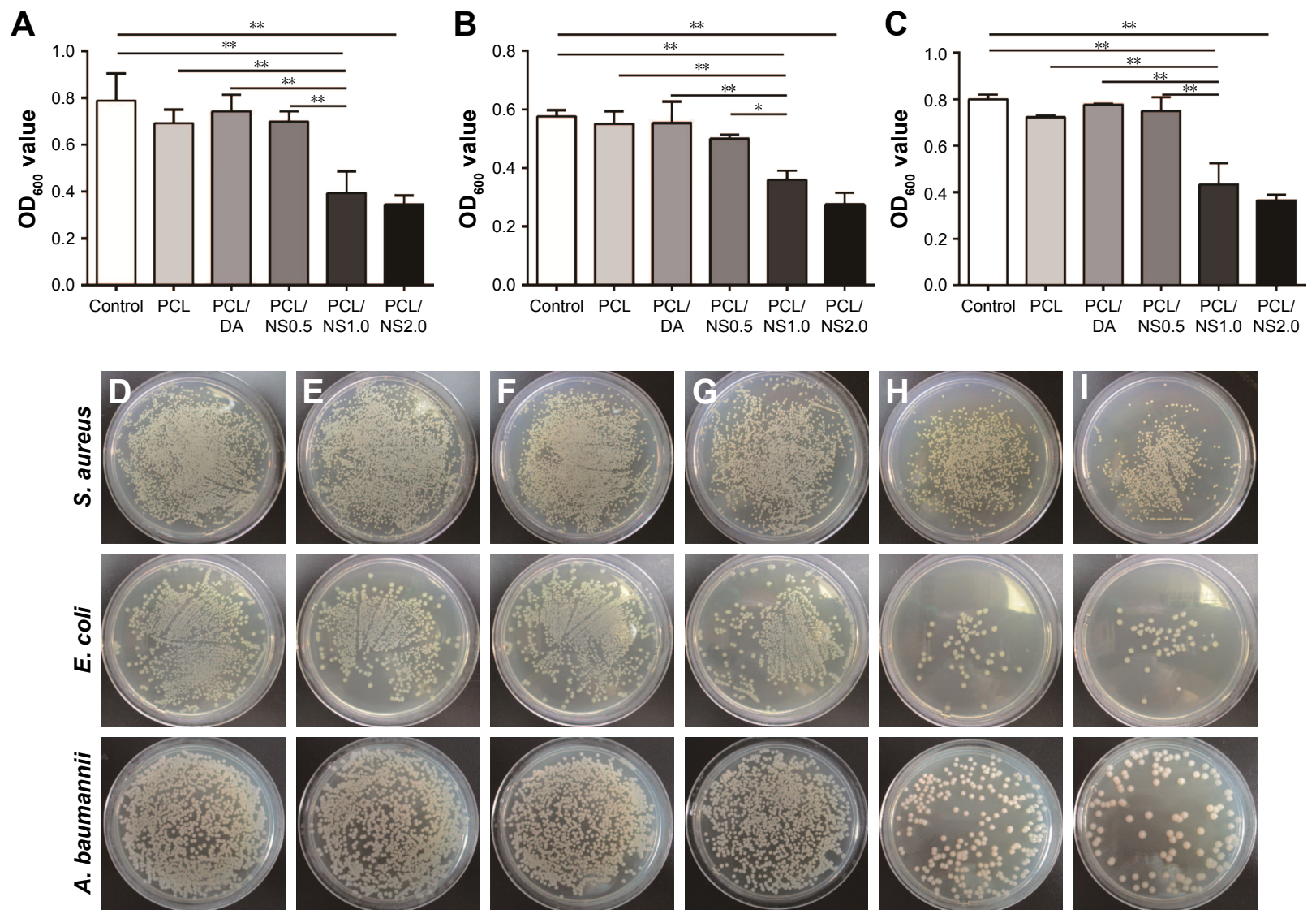

Figure $5 \mathrm{OD}_{600}$ values of $(\mathbf{A})$ S. aureus, (B) E. coli and (C) A. baumannii bacterial suspensions after $24 \mathrm{~h}$ of co-incubation with samples. Data are presented as mean $\pm \mathrm{SD}$ ( $\mathrm{n}=3$ ). The detection of survival bacteria in the bacterial suspensions from the (D) control, (E) PCL, (F) PCL/DA, (G) PCL/NS0.5, (H) PCL/NSI.0 and (I) PCL/NS2.0 groups. Notes: $* p<0.05$ and ${ }^{* *} p<0.01$.

Abbreviations: A. baumannii, Acinetobacter baumannii; DA, dopamine; E. coli, Escherichia coli; NS, nanosilver; OD, optical density; PCL, polycaprolactone; S. aureus, Staphylococcus aureus.

\section{Effect of the PCL/NSI.0 on the healing of infectious wound in vivo}

The effect of PCL/NS1.0 nanofibrous mesh on the healing of infectious wound was detected by an infectious murine fullthickness skin defect wound model. As shown in Figure 9, no significant difference was observed in the wound closure area among all the groups at day 1 post surgery. Nevertheless, at day 3 post surgery, thick yellow pus was found in the wounds of the control, PCL and PCL/DA groups (Figure 9A). In addition, the skin around the wounds was obviously red and swollen in those groups. However, exudate was seldom found in the wounds of blank and PCL/NS1.0 groups, and the area of wound closure in these groups was significantly larger than that in the PCL group. At days 5 and 7, there were still plenty of purulent exudates in the wounds of the control, PCL and PCL/DA groups, and the wound healing area in these groups was significantly lower than the blank and PCL/NS1.0 groups. After 7 days, the area of wound closure was $78.7 \%, 55.3 \%, 38.3 \%, 48.5 \%$ and $77.8 \%$ in the blank, control, PCL, PCL/DA and PCL/NS1.0 groups, respectively (Figure 9B). No significant difference in the area of wound closure was observed between the blank and PCL/NS1.0 groups at all days.

The length of newly generated epidermis at day 7 post surgery was further histologically analyzed by $\mathrm{H} \& \mathrm{E}$ staining. The results showed that the length of neo-formed epithelium was significantly longer in the blank and PCL/NS1.0 groups than that in the control, PCL and PCL/DA groups (Figure 10).

\section{Effect of PCL/NSI.0 on keratinocyte proliferation}

As PCL/NS1.0 nanofibrous mesh could promote reepithelialization (Figure 10), we further investigated the underlying mechanism, and the PCNA levels in keratinocytes were detected by immunohistochemistry. We could found more PCNA-positive keratinocytes at the wound edge in the blank and PCL/NS1.0 groups, compared with other groups, 
A


PCL

B




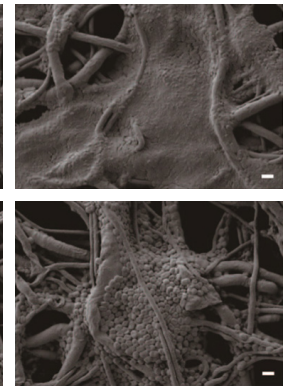

PCL/DA
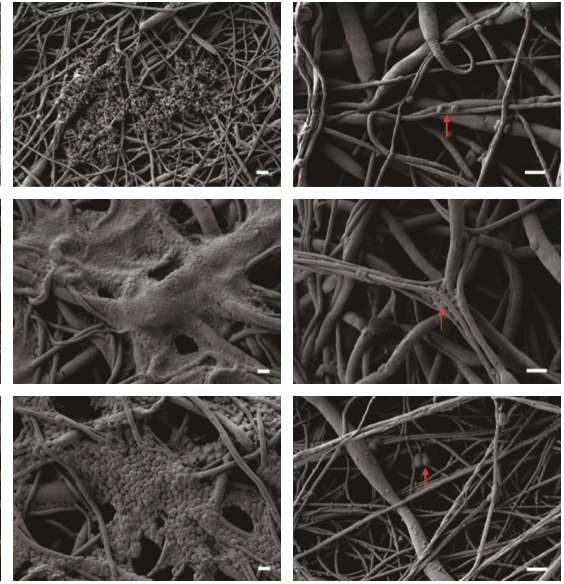

PCL/NS0.5

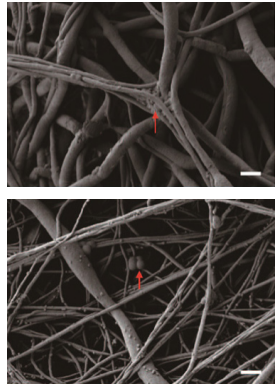

PCL/NS1.0
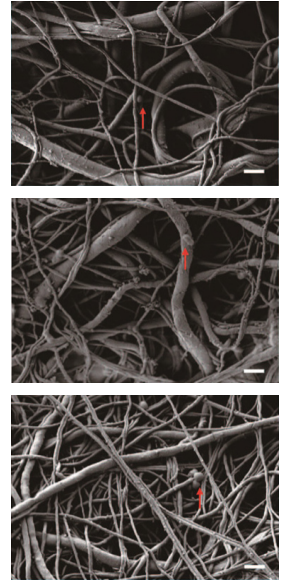

PCL/NS2.0
C

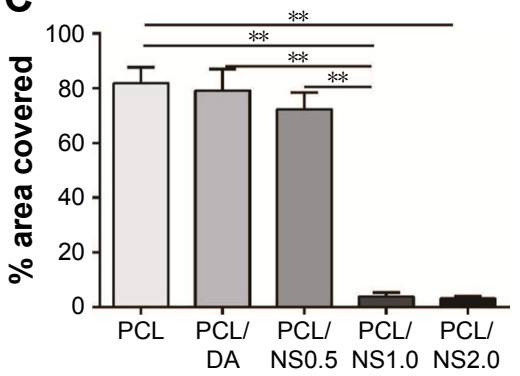

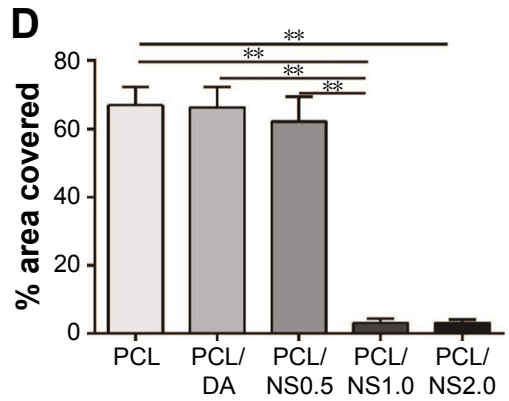

Figure 6 The effect of PCL/NS on the formation of biofilms.

Notes: (A) SEM morphology of biofilms on the surfaces of PCL, PCL/DA, PCL/NS0.5, PCL/NSI.0 and PCL/NS2.0; the red arrows indicate the adherent bacteria. The quantitative area covered by the biofilms of (B) S. aureus, (C) E. coli and (D) A. baumannii. Scale bars: I $\mu$ m. Magnification of images in PCL, PCL/DA and PCL/NS0.5 groups are $\times 3,000$, and the magnification of images in PCL/NSI.0 and PCL/NS2.0 groups are $\times 5,000$. ** $p<0.01$.

Abbreviations: A. baumannii, Acinetobacter baumannii; DA, dopamine; E. coli, Escherichia coli; NS, nanosilver; PCL, polycaprolactone; S. aureus, Staphylococcus aureus; SEM, scanning electron microscopy.

as shown in Figure 11. Moreover, the statistical analysis result also revealed that the number of positive keratinocytes per field was higher in the blank and PCL/NS1.0 groups than that in other groups.
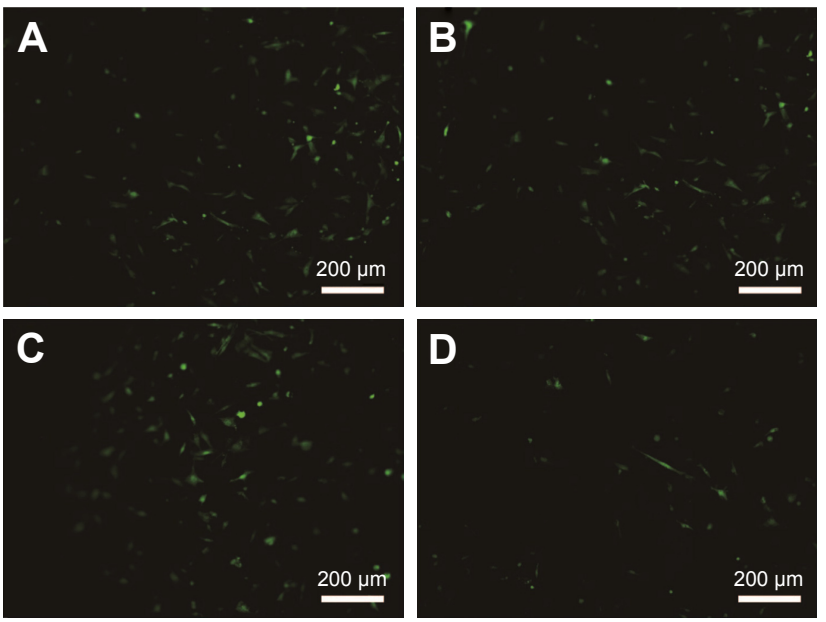

\section{Effect of PCL/NSI.0 on inflammation in vivo}

To investigate the effect of PCL/NS1.0 on inflammation, the inflammatory cells infiltrated in the subcutaneous areas of

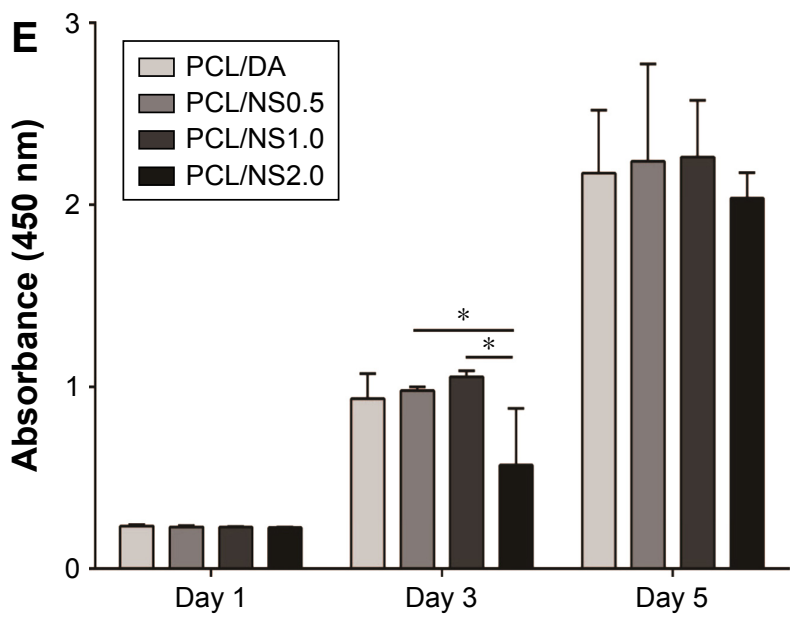

Figure 7 Fluorescence microscopy images of GFP transgenic fibroblasts on the (A) PCL/DA, (B) PCL/NS0.5, (C) PCL/NSI.0 and (D) PCL/NS2.0 films; (E) the cell viability measured using CCK8 assay at days I, 3 and 5 post seeding.

Note: Magnification $\times 200$. $* p<0.05$.

Abbreviations: CCK8, Cell Counting Kit-8; DA, dopamine; GFP, green fluorescent protein; NS, nanosilver; PCL, polycaprolactone. 


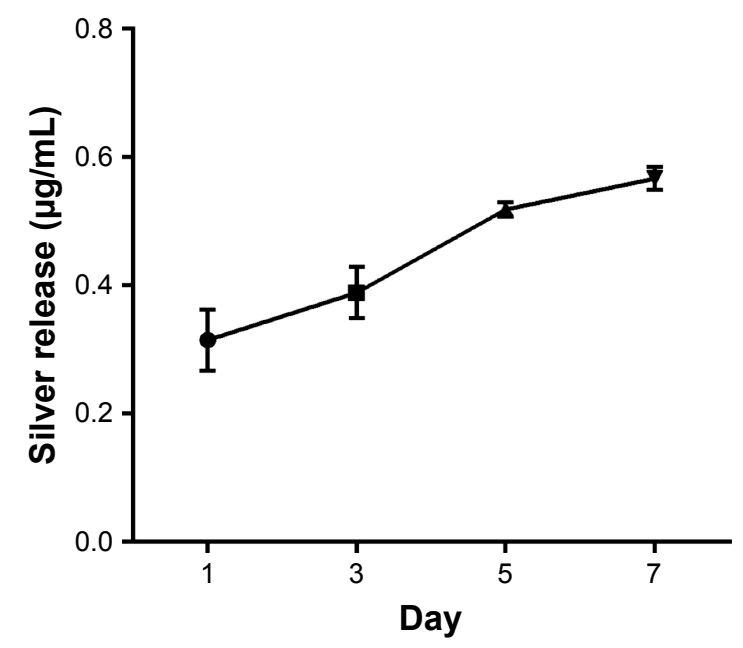

Figure 8 Silver ion release profile of PCL/NS at days I, 3, 5 and 7.

Note: Data are presented as mean $\pm \operatorname{SD}(n=3)$.

Abbreviations: NS, nanosilver; PCL, polycaprolactone.

wound edge after 7 days have been histologically analyzed and counted. As shown in Figure 12, the number of inflammatory cells infiltrated in the wound edge was much more in the control, PCL and PCL/DA groups than that in the PCL/NS1.0 group, but no significant difference was observed between the blank and PCL/NS1.0 groups.

\section{Discussion}

Cutaneous wounds that are infected or at risk of infection are known to be a global issue. ${ }^{1,45}$ Management of wound dressings containing antibacterial agents is expected to be a feasible way to solve the problem. ${ }^{1}$ However, improper use of antibiotics has led to serious antibiotic resistance problem, so it is necessary to find an alternative approach. To meet this demand, a PCL nanofibrous mesh impregnated with NS nanocomposite was prepared using environmentally friendly and mussel-inspired DA in this work (Figure 1).

The SEM results showed that the prepared PCL/NS0.5, PCL/NS1.0 and PCL/NS2.0 had a three-dimensional network structure, and the nanofibers were uniformly decorated with several spherical NSs (Figure 2). This result is caused by the reducibility of catechol group in DA, which could efficiently benefit for the silver reduction without destroy the primary scaffold structure. ${ }^{18,46}$ To further investigate the surface chemical structure of PCL/NS after DA coating and NS deposition, the FTIR analysis was used. As shown in Figure 3 , the results demonstrated the successful DA coating and NS formation. Because the surface hydrophilicity could influence the biological behavior of scaffold material, ${ }^{46}$ water contact angle was measured subsequently. We found that the water contact angle was significantly lower on the PCL/ DA, PCL/NS0.5, PCL/NS1.0 and PCL/NS2.0 films than that on the pristine PCL (Figure 4), indicating that the surface hydrophilicity was obviously improved after DA coating and NS deposition, which might be helpful for better cytocompatibility. Overall, PCL/NS was successfully fabricated, and the surface structure was well improved.

To detect the antibacterial activity of prepared wound dressing in vitro, the bacterial suspension assay was used and
A

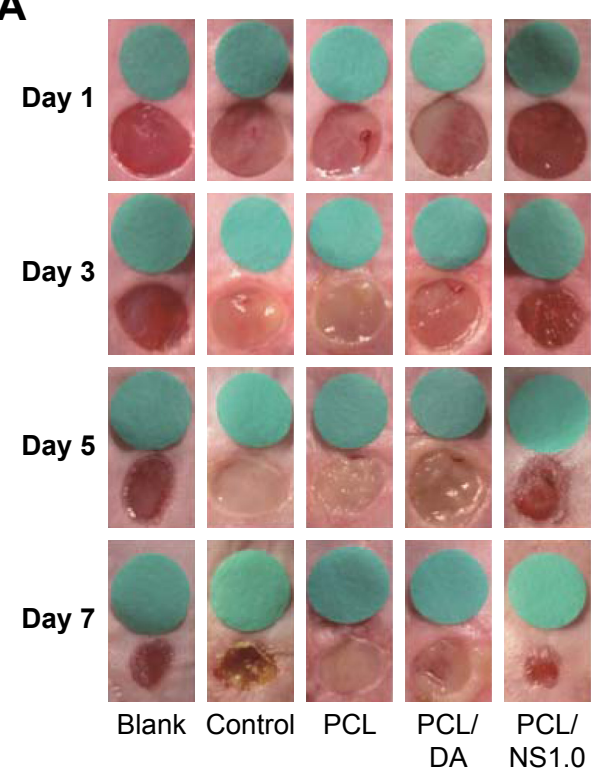

B

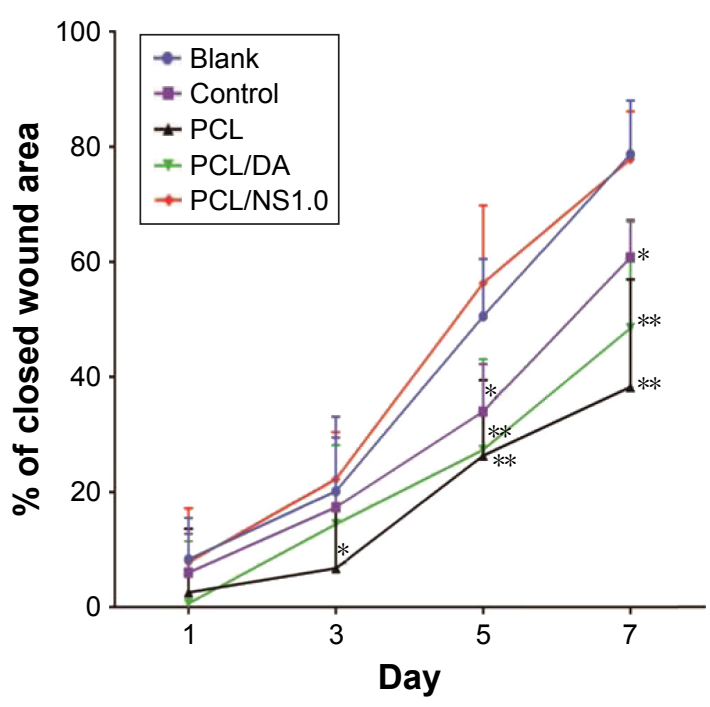

Figure 9 The effect of PCL/NSI.0 on the healing of infectious wounds.

Notes: (A) The representative macroscopic appearance of wounds from the blank, control, PCL, PCL/DA and PCL/NSI .0 groups. (B) The closed wound area at predetermined time points. Data are presented as mean $\pm S D(n=5)$. The significant difference between PCL/NSI.0 and the control, PCL and PCL/DA groups, ${ }^{*}<<0.05, * * p<0.0$ I. Abbreviations: DA, dopamine; NS, nanosilver; PCL, polycaprolactone. 

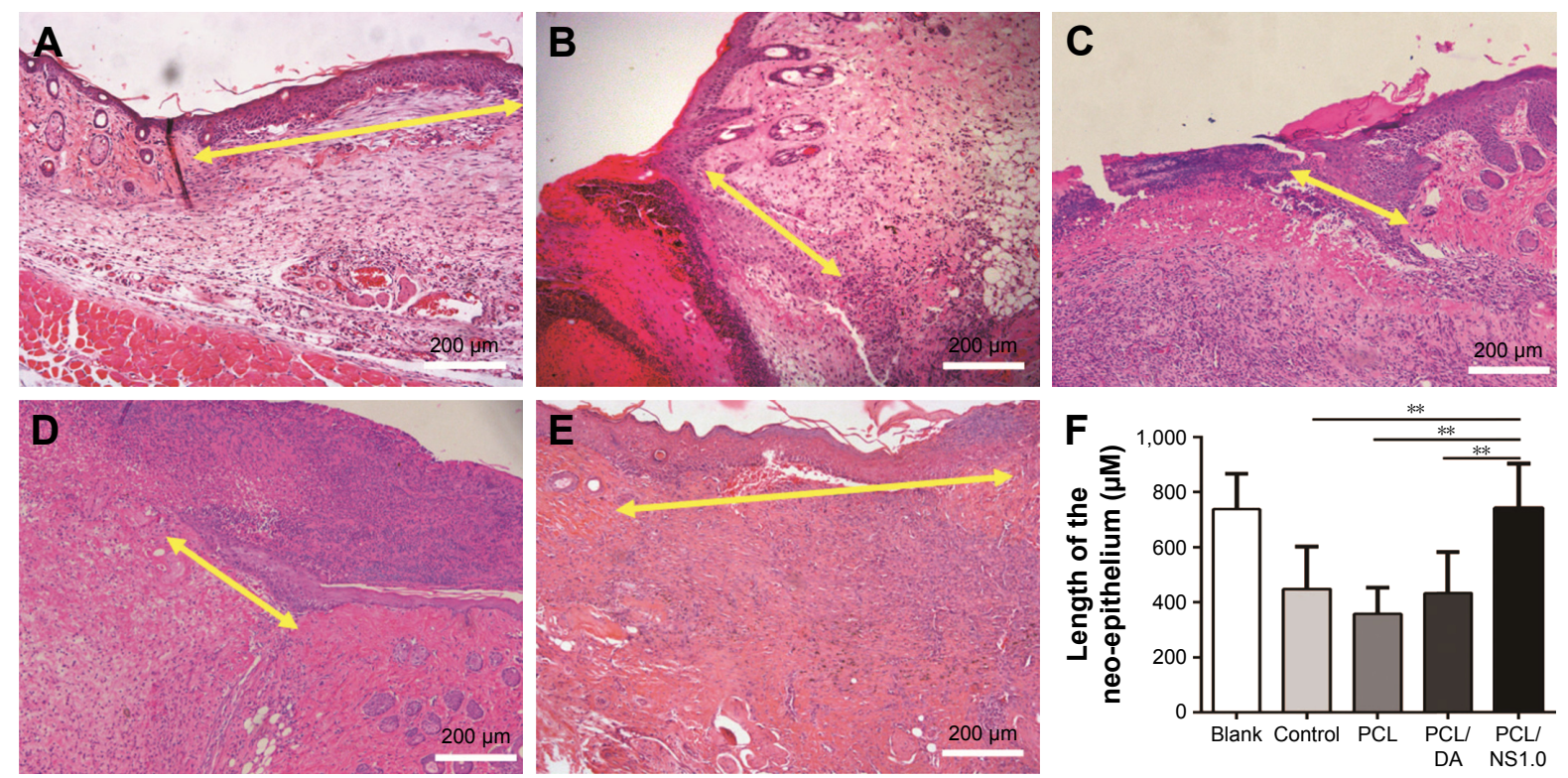

Figure 10 The effect of PCL/NSI.0 on re-epithelialization.

Notes: Representative histological images of the length of the newly generated epidermis taken at day 7 post surgery in the (A) blank, (B) control, (C) PCL, (D) PCL/DA and (E) PCL/NSI.0 groups. The yellow double-headed arrows refer to the length of the newly generated epidermis. (F) Calculation of the length of the newly generated epidermis at day 7 post surgery. Data are presented as mean $\pm S D(n=4)$, and the significant difference between the PCL/NSI.0 group and the control, PCL or PCL/DA group, $* * p<0.0$ I. Scale bars: $200 \mu \mathrm{m}$. Magnification $\times 100$.

Abbreviations: DA, dopamine; NS, nanosilver; PCL, polycaprolactone.

the biofilms formation was detected. As shown in Figure 5, the $\mathrm{OD}_{600}$ values of the PCL/NS1.0 and PCL/NS2.0 groups were significantly lower than those of other groups for the E. coli, A. baumannii (Gram-negative bacteria) and S. aureus (Gram-positive bacteria), indicating that they had good and broad-spectrum antibacterial property. Furthermore, the count of bacterial colonies was also less in the PCL/NS1.0 and PCL/NS2.0 groups, demonstrating the released NS from the two films could efficiently inhibit the growth of bacteria. More importantly, PCL/NS1.0 and PCL/NS2.0 could also inhibit the formation of biofilms (Figure 6), which is essential for a wound dressing in practical application. ${ }^{1}$ This may be because that NS-containing biomaterials could fight bacterial adhesion and clonal growth. ${ }^{30,47}$ Although the bactericidal mechanisms of NS are not fully understood, ${ }^{8}$ a possible explanation for the excellent antibacterial activities of PCL/NS1.0 and PCL/NS2.0 could be speculated based on previous reports and our results as follows: NSs have nanodimensions of 1-100 $\mathrm{nm}$ and large surface-to-volume ratio. The NS can interact with the sulfur-containing biomolecules of bacterial membrane protein and cause structural changes and damages to the cell membrane. ${ }^{48,49}$ Moreover, the interaction between NS and thiol groups of protein may induce the release of reactive oxygen species (ROS), which then inhibits the respiratory enzymes and consequently leads to cell death. ${ }^{50,51}$ In addition, the silver ions $\left(\mathrm{Ag}^{+}\right)$released from the NS are able to bind to the negative charge of bacterial cell wall and render bacteria more permeable. ${ }^{52}$ Then, silver ions and NS enter the bacterial cell body and damage the sulfhydryl group in protein, which severely interfere with the DNA replication, causing cell death in the end. ${ }^{53}$ As shown in Figure 2, the diameter of NS (approximately $70 \mathrm{~nm}$ ) incorporated into the PCL mesh was well below $100 \mathrm{~nm}$, meaning that the bacterial membrane that contacted with the film could be efficiently damaged by the nanoparticles and finally leads to the cell death. ${ }^{8}$ Furthermore, the silver ion release profile of $\mathrm{PCL} / \mathrm{NS} 1.0$ revealed that silver ions rapidly released at day 1 and the concentration of silver ions $(0.32 \mu \mathrm{g} / \mathrm{mL})$ is enough to kill bacteria. ${ }^{54,55}$ In addition, after 3, 5 and 7 days, constant silver release was still observed, meaning that bacterial inhibition efficacy of PCL/NS1.0 was prolonged and effective. Therefore, it suggests that PCL/NS1.0 may inhibit bacterial growth by destroying the bacterial membrane and DNA, as well as inhibiting respiratory enzyme activity.

The cytotoxicity was a main concern for the application of NS, so the cell morphology observation and CCK8 assay were used for toxic evaluation. As shown in Figure 7A-D, at day 3 post seeding, a lot of fibroblasts grew well on the surface of PCL/DA, PCL/NS0.5 and PCL/NS1.0 films, but cells were seldom observed on the surface of PCL/NS2.0 film. This indicated that the PCL/NS2.0 film was harmful for the cell growth. Then, the CCK8 result also showed that 

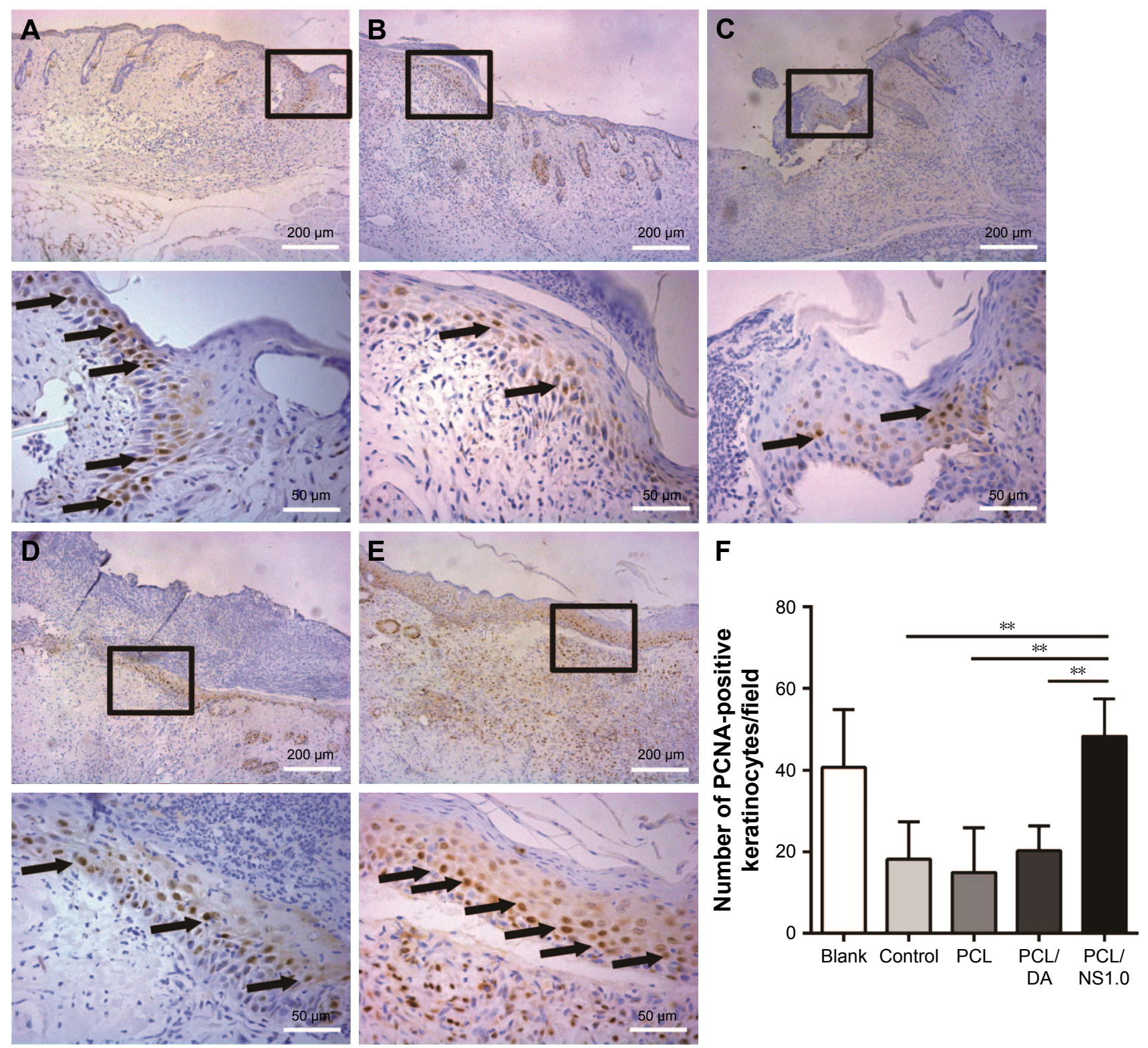

Figure II The expression of PCNA in keratinocytes on the edge of wound at day 7 post surgery.

Notes: Representative images of immunohistochemical staining of PCNA taken from the (A) blank, (B) control, (C) PCL, (D) PCL/DA and (E) PCL/NSI.0 groups. The rectangular insets represent the magnified areas, while the black arrows indicate PCNA-positive keratinocytes. (F) Counting of PCNA-positive keratinocytes per field in newly generated epidermis. Data are presented as mean \pm SD $(n=4)$. Scale bars: $200 \mu \mathrm{m}$ (low magnification $\times 100)$ and $50 \mu \mathrm{m}($ high magnification $\times 400)$. $* *<<0.01$.

Abbreviations: DA, dopamine; NS, nanosilver; PCL, polycaprolactone; PCNA, proliferating cell nuclear antigen.

the cell viability in the PCL/NS2.0 group was worse than the PCL/NS0.5 and PCL/NS1.0 groups (Figure 7E), which further indicated the obvious cytotoxicity of PCL/NS2.0. Nevertheless, the cell viability in PCL/DA was similar with the PCL/NS0.5 and PCL/NS1.0 groups at days 1, 3 and 5 , suggesting that the NS in the PCL/NS0.5 and PCL/NS1.0 films could not cause significant cytotoxicity. In line with this result, Figure 8 shows that total silver concentration after 7 days was approximately $0.57 \mu \mathrm{g} / \mathrm{mL}$, which was well below the toxic concentration of human body $(10 \mu \mathrm{g} / \mathrm{mL}){ }^{56}$ suggesting that the PCL/NS1.0 was biocompatible with human beings. Therefore, these results indicated that the cytotoxicity of NS occurred at high concentration as previously described. ${ }^{11,12}$

Because of effective antibacterial activity without observed cytotoxicity, PCL/NS1.0 was chosen as the optimized film for the next experiments. The abovementioned results also demonstrated that an optimized concentration of NS was successfully found as expected.

Finally, the real effect of PCL/NS1.0 on bacterial invasion and wound healing in vivo was detected using an infectious murine full-thickness skin defect wound model. 

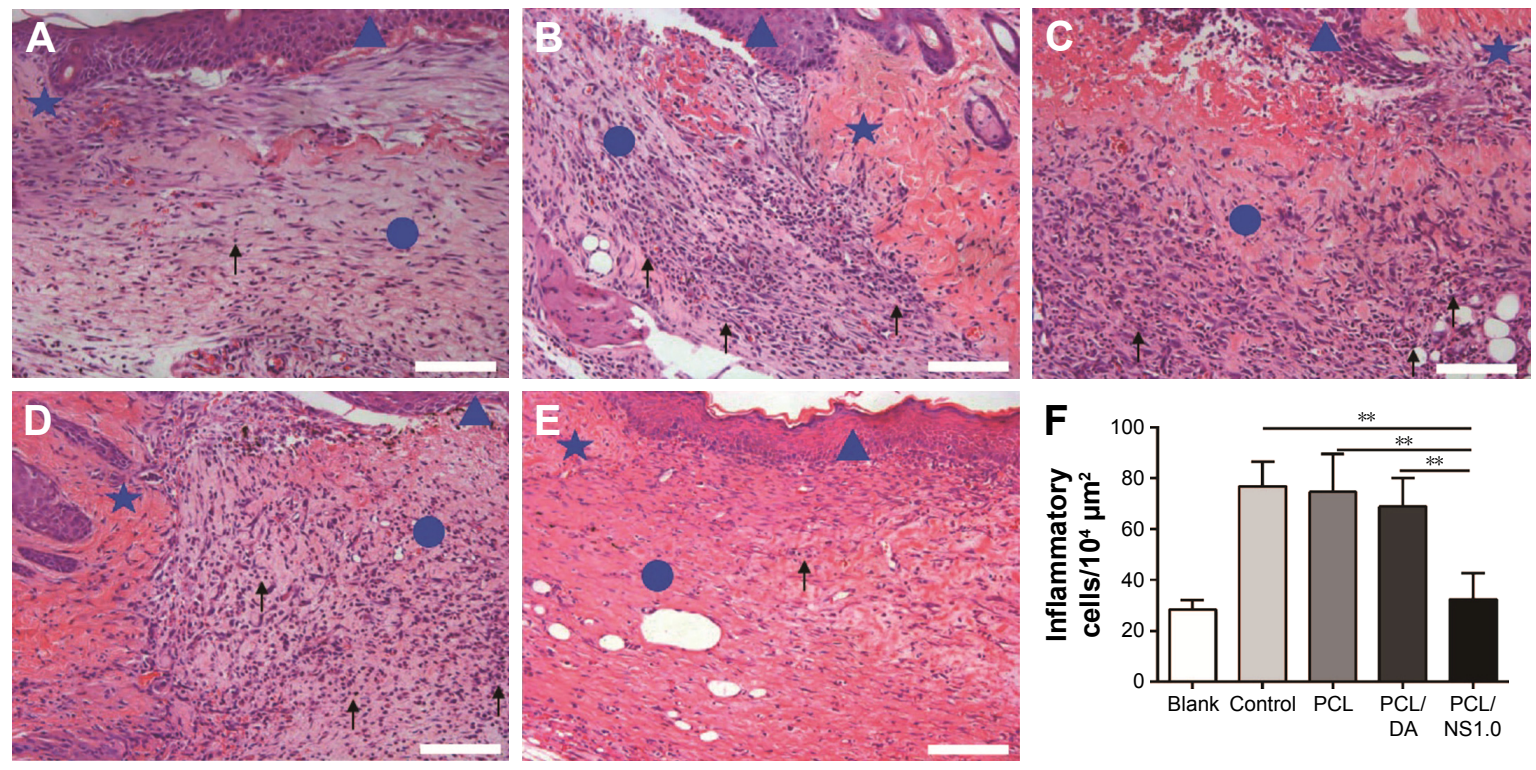

Figure 12 The inflammatory cells infiltrated in the subcutaneous areas of wound edge at day 7 post surgery.

Notes: Representative H\&E staining images of the (A) blank, (B) control, (C) PCL, (D) PCL/DA and (E) PCL/NSI.0 groups. The triangle represents the newly formed epidermis, the circle represents the wound area, and the pentagram represents unwounded skin tissue. The black arrows indicate the inflammatory cells. (F) Counting of inflammatory cells infiltrated in the subcutaneous areas of wound edge. Data are presented as mean \pm SD $(n=4)$. Scale bars: $100 \mu$ m. Magnification $\times 200$. $* * p<0.01$.

Abbreviations: DA, dopamine; H\&E, hematoxylin-eosin; NS, nanosilver; PCL, polycaprolactone.

As shown in Figure 9, from day 3 to day 7, the wounds in the control, PCL and PCL/DA groups were full of purulent exudates, indicating that serious infection occurred. However, in the PCL/NS1.0 group, the wounds were clean and no purulent exudate was observed, which was similar with the blank group, suggesting that the PCL/NS1.0 could efficiently inhibit bacterial growth in vivo. At day 7 , about $80 \%$ of wound area has been closed in the blank and PCL/ NS1.0 groups, but the closed wound area was less than $61 \%$ in the control, PCL and PCL/DA groups. This result indicated that infection severely interferes with the normal wound healing in the control, PCL and PCL/DA groups, but coverage of PCL/NS1.0 with effective antibacterial activity could maintain a natural and aseptic microenvironment for wound healing. ${ }^{1}$

Re-epithelialization is a necessary parameter for wound healing, so the length of newly generated epidermis of tissue sections at day 7 post surgery stained with H\&E was histologically analyzed. The results showed that the length of newly regenerated epidermis was significantly longer in the PCL/NS1.0 group than that in the control, PCL and PCL/DA groups, but was similar with that in the blank group (Figure 10). This indicated that PCL/NS1.0 could also accelerate re-epithelialization, which might be due to the good antibacterial activity and biocompatiblility. ${ }^{35,57}$

To further investigate the underlying mechanism, the PCNA protein, a cell proliferation marker, was detected by immunohistochemistry. In line with the promotion of re-epithelialization, we found that PCL/NS1.0 could enhance PCNA expression in keratinocytes, compared with the control, PCL and PCL/DA groups (Figure 11). This was consistent with the previous study that wound dressing containing NS could promote cell proliferation in vivo. ${ }^{35}$ In addition, the effect of PCL/NS1.0 on inflammation in vivo was also detected. The result showed that PCL/NS1.0 could prevent the bacterial infection and the subsequent severe inflammation response (Figure 12), which was benefit for the wound healing. ${ }^{37,58}$

The wound healing is a complex biological process including three stages: inflammation, new tissue regeneration and remodeling. ${ }^{59}$ The active keratinocyte proliferation and fast re-epithelialization are important for the new tissue regeneration, while the bacterial infection is the main cause of impaired healing. ${ }^{1,59,60}$ Wound dressings impregnated with antimicrobials can prevent local bacterial infection and maintain the natural microenvironment for cell proliferation and tissue regeneration to promote wound healing. ${ }^{3,61}$ As described earlier, compared with the control, PCL and PCL/DA groups, the biocompatible PCL/NS1.0 was efficient to protect the wounds from bacterial infection (Figure 9) and maintain a natural and aseptic wound microenvironment without severe inflammation response to promote keratinocyte proliferation (Figures 11 and 12). Thus, the reepithelialization process was much faster in the PCL/NS1.0 
group than that in the control, PCL and PCL/DA groups (Figure 10). Overall, we considered that PCL/NS1.0 with good biocompatibility and antibacterial activity could protect the wounds from bacterial infection and promote wound healing by accelerating re-epithelialization via enhancing keratinocyte proliferation.

\section{Conclusion}

The current study reported an ideal wound dressing prepared by an optimized concentration of NS incorporated into PCL nanofibrous mesh using environmentally friendly DA. This wound dressing was biocompatible and effective for inhibiting bacterial growth both in vitro and in vivo, resulting in rapid re-epithelialization and wound closure in the infectious murine wound model. These results indicated that PCL/ NS1.0 had a promising application in wound management.

\section{Acknowledgments}

This work was supported by the State Key Laboratory Funding (SKLZZ201221) and National Special Scientific Projects of Public Welfare Industry Funding of China (No 201502015).

\section{Disclosure}

The authors report no conflicts of interest in this work.

\section{References}

1. Percival SL, McCarty SM. Silver and alginates: role in wound healing and biofilm control. Adv Wound Care (New Rochelle). 2015;4(7): 407-414.

2. Andrews KL, Houdek MT, Kiemele LJ. Wound management of chronic diabetic foot ulcers: from the basics to regenerative medicine. Prosthet Orthot Int. 2015;39(1):29-39.

3. Turner NJ, Badylak SF. The use of biologic scaffolds in the treatment of chronic nonhealing wounds. Adv Wound Care (New Rochelle). 2015; 4(8):490-500.

4. D'Costa VM, King CE, Kalan L, et al. Antibiotic resistance is ancient. Nature. 2011;477(7365):457-461

5. Walker B, Barrett S, Polasky S, et al. Environment. Looming globalscale failures and missing institutions. Science. 2009;325(5946): 1345-1346.

6. Javani S, Lorca R, Latorre A, Flors C, Cortajarena AL, Somoza A. Antibacterial activity of DNA-stabilized silver nanoclusters tuned by oligonucleotide sequence. ACS Appl Mater Interfaces. 2016;8(16): 10147-10154.

7. Xu D, Wang Q, Yang T, et al. Polyethyleneimine capped silver nanoclusters as efficient antibacterial agents. Int J Environ Res Public Health. 2016;13(3):E334.

8. Franci G, Falanga A, Galdiero S, et al. Silver nanoparticles as potential antibacterial agents. Molecules. 2015;20(5):8856-8874.

9. Chen X, Schluesener HJ. Nanosilver: a nanoproduct in medical application. Toxicol Lett. 2008;176(1):1-12.

10. Pratsinis A, Hervella P, Leroux JC, Pratsinis SE, Sotiriou GA. Toxicity of silver nanoparticles in macrophages. Small. 2013;9(15):2576-2584.

11. Kawata $\mathrm{K}$, Osawa $\mathrm{M}$, Okabe $\mathrm{S}$. In vitro toxicity of silver nanoparticles at noncytotoxic doses to HepG2 human hepatoma cells. Environ $\mathrm{Sci}$ Technol. 2009;43(15):6046-6051.
12. Pauksch L, Hartmann S, Rohnke M, et al. Biocompatibility of silver nanoparticles and silver ions in primary human mesenchymal stem cells and osteoblasts. Acta Biomater. 2014;10(1):439-449.

13. Jia Z, Xiu P, Li M, et al. Bioinspired anchoring AgNPs onto micronanoporous TiO2 orthopedic coatings: trap-killing of bacteria, surfaceregulated osteoblast functions and host responses. Biomaterials. 2016;75:203-222.

14. Gurunathan S, Park JH, Han JW, Kim JH. Comparative assessment of the apoptotic potential of silver nanoparticles synthesized by Bacillus tequilensis and Calocybe indica in MDA-MB-231 human breast cancer cells: targeting p53 for anticancer therapy. Int J Nanomedicine. 2015; 10:4203-4222.

15. Shameli K, Ahmad MB, Yunus WM, Ibrahim NA, Gharayebi Y, Sedaghat S. Synthesis of silver/montmorillonite nanocomposites using gamma-irradiation. Int J Nanomedicine. 2010;5:1067-1077.

16. Wu C, Zhang G, Xia T, et al. Bioinspired synthesis of polydopamine/ Ag nanocomposite particles with antibacterial activities. Mater Sci Eng C Mater Biol Appl. 2015;55:155-165.

17. Messersmith PB. Materials science. Multitasking in tissues and materials. Science. 2008;319(5871):1767-1768.

18. Lee H, Dellatore SM, Miller WM, Messersmith PB. Mussel-inspired surface chemistry for multifunctional coatings. Science. 2007;318(5849): 426-430.

19. Kaushik NK, Kaushik N, Pardeshi S, Sharma JG, Lee SH, Choi EH. Biomedical and clinical importance of mussel-inspired polymers and materials. Mar Drugs. 2015;13(11):6792-6817.

20. Ku SH, Park CB. Human endothelial cell growth on mussel-inspired nanofiber scaffold for vascular tissue engineering. Biomaterials. 2010; 31(36):9431-9437.

21. Madhurakkat Perikamana SK, Lee J, Lee YB, et al. Materials from mussel-inspired chemistry for cell and tissue engineering applications. Biomacromolecules. 2015;16(9):2541-2555.

22. Xu R, Luo G, Xia H, et al. Novel bilayer wound dressing composed of silicone rubber with particular micropores enhanced wound re-epithelialization and contraction. Biomaterials. 2015;40:1-11.

23. Fu SZ, Meng XH, Fan J, et al. Acceleration of dermal wound healing by using electrospun curcumin-loaded poly(epsilon-caprolactone)poly(ethylene glycol)-poly(epsilon-caprolactone) fibrous mats. J Biomed Mater Res B Appl Biomater. 2014;102(3):533-542.

24. Chong EJ, Phan TT, Lim IJ, et al. Evaluation of electrospun PCL/ gelatin nanofibrous scaffold for wound healing and layered dermal reconstitution. Acta Biomater. 2007;3(3):321-330.

25. Yao Q, Cosme JG, Xu T, et al. Three dimensional electrospun PCL/ PLA blend nanofibrous scaffolds with significantly improved stem cells osteogenic differentiation and cranial bone formation. Biomaterials. 2017;115:115-127.

26. Jiang J, Wan W, Ge L, Bu S, Zhong W, Xing M. Mussel-inspired nanofibrous sheet for suture-less stomach incision surgery. Chem Commun. 2015;51(41):8695-8698.

27. GhavamiNejad A, Rajan Unnithan A, Ramachandra Kurup Sasikala A, et al. Mussel-inspired electrospun nanofibers functionalized with sizecontrolled silver nanoparticles for wound dressing application. ACS Appl Mater Interfaces. 2015;7(22):12176-12183.

28. Bolgen N, Vargel I, Korkusuz P, Menceloglu YZ, Piskin E. In vivo performance of antibiotic embedded electrospun PCL membranes for prevention of abdominal adhesions. J Biomed Mater Res B Appl Biomater. 2007;81(2):530-543.

29. Reithofer MR, Lakshmanan A, Ping AT, Chin JM, Hauser CA. In situ synthesis of size-controlled, stable silver nanoparticles within ultrashort peptide hydrogels and their anti-bacterial properties. Biomaterials. 2014;35(26):7535-7542.

30. Qin $\mathrm{H}$, Cao H, Zhao Y, et al. In vitro and in vivo anti-biofilm effects of silver nanoparticles immobilized on titanium. Biomaterials. 2014; 35(33):9114-9125.

31. Gnanadhas DP, Elango M, Janardhanraj S, et al. Successful treatment of biofilm infections using shock waves combined with antibiotic therapy. Sci Rep. 2015;5:17440. 
32. Cheng B, Liu HW, Fu XB, Sheng ZY, Li JF. Coexistence and upregulation of three types of opioid receptors, mu, delta and kappa, in human hypertrophic scars. Br J Dermatol. 2008;158(4):713-720.

33. Wang Y, Chen Z, Luo G, et al. In-situ-generated vasoactive intestinal peptide loaded microspheres in mussel-inspired polycaprolactone nanosheets creating spatiotemporal releasing microenvironment to promote wound healing and angiogenesis. ACS Appl Mater Interfaces. 2016;8(11):7411-7421.

34. El-Naggar MY, Gohar YM, Sorour MA, Waheeb MG. Hydrogel dressing with a nano-formula against Methicillin-resistant Staphylococcus aureus and Pseudomonas aeruginosa diabetic foot bacteria. J Microbiol Biotechnol. 2016;26(2):408-420.

35. Liu M, Luo G, Wang Y, et al. Nano-silver-decorated microfibrous eggshell membrane: processing, cytotoxicity assessment and optimization, antibacterial activity and wound healing. Sci Rep. 2017;7(1):436.

36. Wang Y, Xu R, Luo G, et al. Biomimetic fibroblast-loaded artificial dermis with "sandwich" structure and designed gradient pore sizes promotes wound healing by favoring granulation tissue formation and wound re-epithelialization. Acta Biomater. 2016;30:246-257.

37. Xu Q, Zheng Z, Wang B, Mao H, Yan F. Zinc ion coordinated poly(ionic liquid) antimicrobial membranes for wound healing. ACS Appl Mater Interfaces. 2017;9(17):14656-14664.

38. Tran PA, Hocking DM, O'Connor AJ. In situ formation of antimicrobial silver nanoparticles and the impregnation of hydrophobic polycaprolactone matrix for antimicrobial medical device applications. Mater Sci Eng C Mater Biol Appl. 2015;47:63-69.

39. Thomas R, Soumya KR, Mathew J, Radhakrishnan EK. Electrospun polycaprolactone membrane incorporated with biosynthesized silver nanoparticles as effective wound dressing material. Appl Biochem Biotechnol. 2015;176(8):2213-2224.

40. Liang M, Su R, Huang R, et al. Facile in situ synthesis of silver nanoparticles on procyanidin-grafted eggshell membrane and their catalytic properties. ACS Appl Mater Interfaces. 2014;6(7):4638-4649.

41. Flemming HC, Wingender J. The biofilm matrix. Nat Rev Microbiol. 2010;8(9):623-633.

42. Vasilev K, Cook J, Griesser HJ. Antibacterial surfaces for biomedical devices. Expert Rev Med Devices. 2009;6(5):553-567.

43. Antoci V Jr, Adams CS, Parvizi J, et al. The inhibition of Staphylococcus epidermidis biofilm formation by vancomycin-modified titanium alloy and implications for the treatment of periprosthetic infection. Biomaterials. 2008;29(35):4684-4690.

44. Kostenko V, Lyczak J, Turner K, Martinuzzi RJ. Impact of silvercontaining wound dressings on bacterial biofilm viability and susceptibility to antibiotics during prolonged treatment. Antimicrob Agents Chemother. 2010;54(12):5120-5131.

45. Percival SL, McCarty SM, Lipsky B. Biofilms and wounds: an overview of the evidence. Adv Wound Care (New Rochelle). 2015;4(7): $373-381$.
46. Liu M, Zeng G, Wang K, et al. Recent developments in polydopamine: an emerging soft matter for surface modification and biomedical applications. Nanoscale. 2016;8(38):16819-16840.

47. van Hengel IAJ, Riool M, Fratila-Apachitei LE, et al. Selective laser melting porous metallic implants with immobilized silver nanoparticles kill and prevent biofilm formation by methicillin-resistant Staphylococcus aureus. Biomaterials. 2017;140:1-15.

48. Feng QL, Wu J, Chen GQ, Cui FZ, Kim TN, Kim JO. A mechanistic study of the antibacterial effect of silver ions on Escherichia coli and Staphylococcus aureus. J Biomed Mater Res. 2000;52(4):662-668.

49. Lazar V. Quorum sensing in biofilms - how to destroy the bacterial citadels or their cohesion/power? Anaerobe. 2011;17(6):280-285.

50. Ninganagouda S, Rathod V, Singh D, et al. Growth kinetics and mechanistic action of reactive oxygen species released by silver nanoparticles from Aspergillus niger on Escherichia coli. Biomed Res Int. 2014;2014:753419.

51. Holt KB, Bard AJ. Interaction of silver(I) ions with the respiratory chain of Escherichia coli: an electrochemical and scanning electrochemical microscopy study of the antimicrobial mechanism of micromolar Ag+. Biochemistry. 2005;44(39):13214-13223.

52. Patil SV, Borase HP, Patil CD, Salunke BK. Biosynthesis of silver nanoparticles using latex from few Euphorbian plants and their antimicrobial potential. Appl Biochem Biotechnol. 2012;167(4):776-790.

53. Seth D, Choudhury SR, Pradhan S, et al. Nature-inspired novel drug design paradigm using nanosilver: efficacy on multi-drug-resistant clinical isolates of tuberculosis. Curr Microbiol. 2011;62(3):715-726.

54. Shameli K, Ahmad MB, Yunus WM, et al. Silver/poly (lactic acid) nanocomposites: preparation, characterization, and antibacterial activity. Int J Nanomedicine. 2010;5:573-579.

55. Xiu ZM, Ma J, Alvarez PJ. Differential effect of common ligands and molecular oxygen on antimicrobial activity of silver nanoparticles versus silver ions. Environ Sci Technol. 2011;45(20):9003-9008.

56. Schierholz JM, Lucas LJ, Rump A, Pulverer G. Efficacy of silver-coated medical devices. J Hosp Infect. 1998;40(4):257-262.

57. Demling RH, Leslie DeSanti MD. The rate of re-epithelialization across meshed skin grafts is increased with exposure to silver. Burns. 2002;28(3):264-266.

58. Zhi Z, Su Y, Xi Y, et al. Dual-functional polyethylene glycol-bpolyhexanide surface coating with in vitro and in vivo antimicrobial and antifouling activities. ACS Appl Mater Interfaces. 2017;9(12): 10383-10397.

59. Gurtner GC, Werner S, Barrandon Y, Longaker MT. Wound repair and regeneration. Nature 2008;453(7193):314-321.

60. Lee SH, Zahoor M, Hwang JK, Min do S, Choi KY. Valproic acid induces cutaneous wound healing in vivo and enhances keratinocyte motility. PLoS One. 2012;7(11):e48791.

61. Mogosanu GD, Grumezescu AM. Natural and synthetic polymers for wounds and burns dressing. Int J Pharm. 2014;463(2):127-136.
International Journal of Nanomedicine

\section{Publish your work in this journal}

The International Journal of Nanomedicine is an international, peerreviewed journal focusing on the application of nanotechnology in diagnostics, therapeutics, and drug delivery systems throughout the biomedical field. This journal is indexed on PubMed Central, MedLine, CAS, SciSearch ${ }^{\circledR}$, Current Contents ${ }^{\circledR} /$ Clinical Medicine,
Dovepress

Journal Citation Reports/Science Edition, EMBase, Scopus and the Elsevier Bibliographic databases. The manuscript management system is completely online and includes a very quick and fair peer-review system, which is all easy to use. Visit http://www.dovepress.com/ testimonials.php to read real quotes from published authors. 